\title{
DDE|PC|95255..TI
}

Task 2 Preliminary Test Plan - November, 1995

\section{MULTIPLE POLLUTANT REMOVAL USING THE CONDENSING HEAT EXCHANGER}

Preliminary Test Plan

For

Task 2 Pilot Scale IFGT Testing

Prepared by:

B. J. Jankura

U. S. DOE Contract - DE-AC22-95PC95255

CRD Contract - 1337

CIEARED BY 
This report was prepared as an account of work sponsored by the United States Government. Neither the United States, any agency thereof, or Babcock and Wilcox, nor any of their employees, makes any warrant, express or implied, or assumes any legal liabilities or responsibility for the accuracy, completeness or usefulness of any information, apparatus, product, or process disclosed, or represents that its use would not infringe privately owned rights. Reference herein to any specific commercial product, process, or service, by trade name, mark, manufacturer, or otherwise, does not necessarily constitute or imply its endorsement, recommendation, or favoring by the United States or any agency thereof. The views and opinions of authors expressed herein do not necessarily state or reflect those of the United States government or any agency thereof. 
Task 2 Preliminary Test Plan - November, 1995

\section{TABLE OF CONTENTS}

$\underline{\text { Section }}$

Page

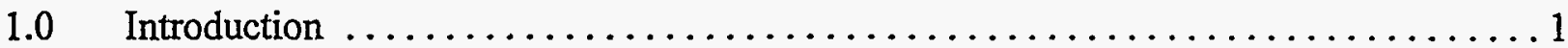

2.0 IFGT Task 2 Test Program Objectives $\ldots \ldots \ldots \ldots \ldots \ldots \ldots \ldots \ldots \ldots \ldots \ldots \ldots \ldots \ldots \ldots \ldots$

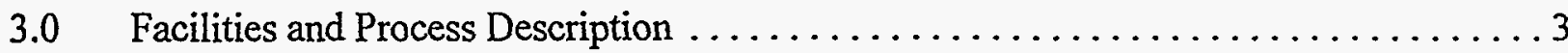

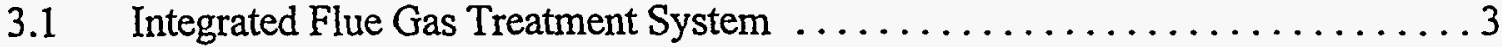

3.2 Small Boiler Simulator Furnace $\ldots \ldots \ldots \ldots \ldots \ldots \ldots \ldots \ldots \ldots \ldots \ldots \ldots \ldots \ldots$

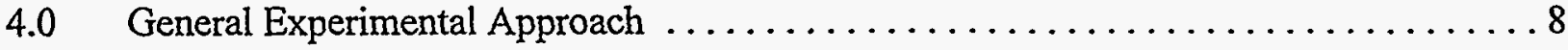

4.1 Facilities Operation and Control $\ldots \ldots \ldots \ldots \ldots \ldots \ldots \ldots \ldots \ldots \ldots \ldots \ldots \ldots \ldots$

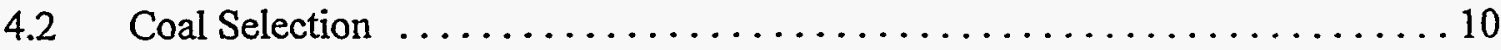

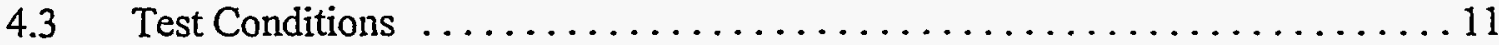

4.3.1 Acid Gas Pollutant Removal ......................... 12

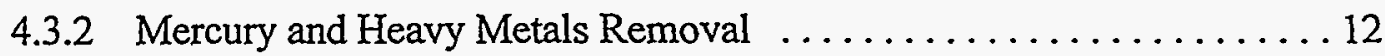

4.3.3 Ammonia Removal ............................... 14

4.3.4 Particulate Removal .................................. 14

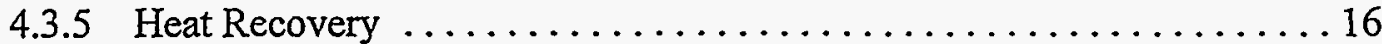

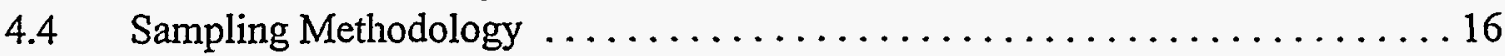

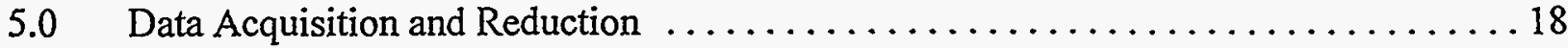

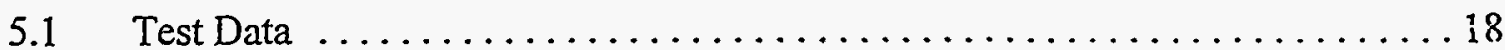

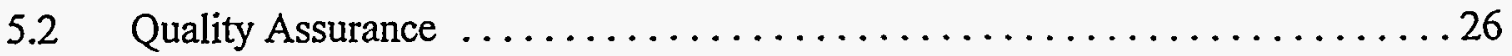

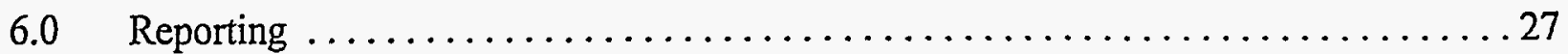

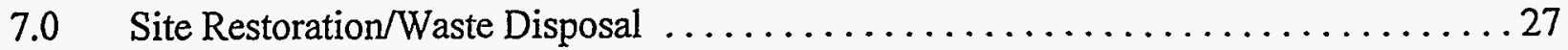


Task 2 Preliminary Test Plan - November, 1995

\section{TABLE OF CONTENTS (CONT'D)}

\section{LIST OF FIGURES}

\section{Page}

1 Process Flow Schematic Of The Pilot IFGT Condensing Heat Exchanger ......... 4

2 Small Boiler Simulator And Condensing Heat Exchanger Test Facilities $\ldots \ldots \ldots \ldots 7$

\section{LIST OF TABLES}

1 Preliminary List of Test Variables and Range of Conditions For The Pollutant Removal Tests ....................................... 15

2 Preliminary IFGT Sampling and Analysis Matrix $\ldots \ldots \ldots \ldots \ldots \ldots \ldots \ldots \ldots \ldots \ldots$

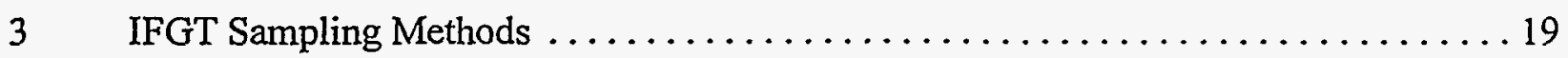

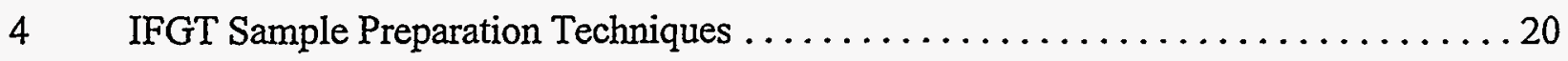

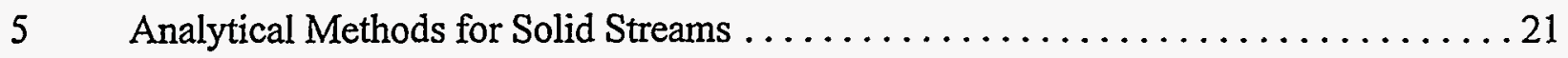

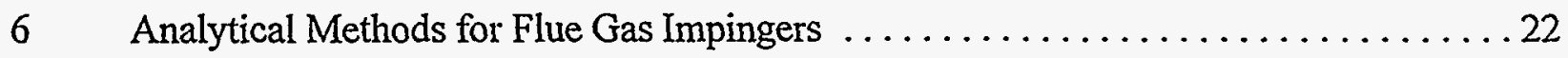

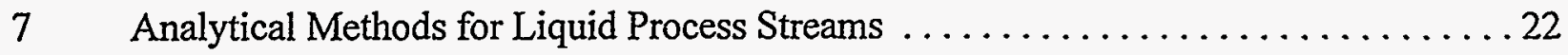

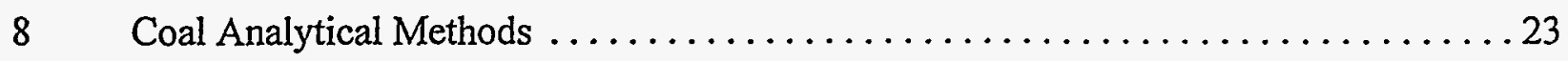

9 IFGT Preliminary Continuous Monitoring Instrumentation $\ldots \ldots \ldots \ldots \ldots 24 / 25$

10 Selected City of Alliance, Ohio Local Discharge Limits $\ldots \ldots \ldots \ldots \ldots \ldots \ldots 28$ 


\subsection{INTRODUCTION}

The purpose of Task 2 (IFGT Pilot-Scale Tests at the B\&W Alliance Research Center) is to evaluate the emission reduction performance of the Integrated Flue Gas Treatment (IFGT) process for coal-fired applications. The IFGT system is a two-stage condensing heat exchanger that captures multiple pollutants - while recovering waste heat. The IFGT technology offers the potential of addressing the emission of $\mathrm{SO}_{2}$ and particulate from electric utilities currently regulated under the Phase I and Phase II requirements defined in Title IV, and many of the air pollutants that will soon be regulated under Title III of the Clean Air Act. The performance data will be obtained at pilot-scale conditions similar to full-scale operating systems.

All Task 2 activities will be conducted at B\&W's Alliance Research Center $0.8 \mathrm{MW}$ pilot-scale IFGT facility. This facility has a flue gas capacity corresponding to a 6 million Btu/hr combustor. Up to four coals will be tested in this Task. These are a high-sulfur Ohio coal, a medium-sulfur coal, a lignite coal, and the coal that is used at EPRI's Environmental Control Technology Center (ECTC). Tests using the ECTC coal will provide data that will be directly applicable to the long-term IFGT testing in Task 3 , and the 5.0 MW IFGT tests in Phase II.

The Task 2 IFGT tests have been designed to investigate several aspects of IFGT process conditions at a broader range of variables than would be feasible at a larger scale facility. The data from these tests greatly expands the IFGT performance database for coals and is needed for the technology to progress from the component engineering phase to system integration and commercialization. The performance parameters that will be investigated are as follows:

$\mathrm{SO}_{2}$ Removal

Particulate removal

Removal of mercury and other heavy metals

$\mathrm{NO}_{\mathrm{x}}$ removal

$\mathrm{HF}$ and $\mathrm{HCl}$ removal

$\mathrm{NH}_{3}$ removal

Ammonia-Sulfur compounds generation

Steam injection for particle removal

For all of the pollutant removal tests, removal efficiency will be based on measurements at the.inlet and outlet of the.IFGT facility. Heat recovery measurements will also be made during these tests to demonstrate the heat recovery provided by the IFGT technology.

This report provides a preliminary test plan for all of the Task 2 pilot-scale IFGT tests. The purpose of the Preliminary Test Plan is to provide a general outline of the type of information and test data that is expected to be collected during the pilot testing. The Preliminary Test Plan ensures that the Final Test Plan can be efficiently compiled to address all 
project objectives and goals. It will be available to test personnel for review so that activities such as facility preparations and materials procurement can be completed in an efficient and timely manner.

The Final Test Plan will be prepared prior to the start of testing. It will include a detailed test schedule and test matrix, which describes the number of tests, the test variables, and measurements to be made. This plan contains a summary of the measurement techniques for each of the four coals. The Final Test Plan will also include detailed information of the measurement techniques, especially with respect to mercury and heavy metals.

\subsection{IFGT TASK 2 TEST PROGRAM OBJECTIVES}

The goal of Task 2 is to develop pollutant removal performance data for the IFGT process that will be applicable to full scale units. The Phase II tests at the ECTC will provide scale-up verification of the pilot-scale data. The tests conducted in this Task will investigate a broader range of variables than would be feasible at a larger scale facility. The overall objectives of these tests are to:

- Demonstrate the pollutant removal performance $\left(\mathrm{SO}_{2}\right.$, particulate, and air toxics) and heat recovery of the integrated flue gas treatment (IFGT) condensing heat exchanger for a range of operating conditions and a variety of coals under controlled conditions.

- Evaluate the potential of operating an IFGT in conjunction with an SCR or SNCR to achieve higher $\mathrm{NO}_{\mathrm{x}}$ removal rates by addressing the problem of ammonia slip.

Specific test program objectives are to:

- Determine the effect of flue gas flow rate, reagent flow rate, flue gas outlet temperature and reagent $\mathrm{pH}$ on $\mathrm{SO}_{2}$ removal.

- Determine the effect of flue gas flow rate and reagent flow rate on particulate removal efficiency as a function of particle size.

- Determine the effect of interstage steam injection on particulate removal efficiency as a function of particle size.

- Measure the effect of reagent flow and outlet flue gas temperature on mercury and heavy metals removal.

- Determine mercury speciation at both the inlet and outlet of the IFGT to quantify total, elemental, and oxidized mercury removal. 
Task 2 Preliminary Test Plan - November, 1995

- Determine the repeatability of mercury and heavy metals removal measurements.

- Determine the fate of $\mathrm{HCl}$ and $\mathrm{HF}$ entering the IFGT system if they are present in the parent coal.

- Measure ammonia removal through the IFGT system.

- Estimate the amount of ammonia that reacts with $\mathrm{SO}_{3}$ before the IFGT system.

- Evaluate the thermal performance of the IFGT in terms of the recovered energy in each cooling stage, and the flow rate of condensed water.

- Obtain waste water samples for later treatment testing.

\subsection{FACILITY AND PROCESS DESCRIPTION}

\subsection{INTEGRATED FLUE GAS TREATMENT SYSTEM}

As shown in Figure 1, the IFGT is essentially a two-pass counter flow shell and tube heat exchanger. The hot flue gas enters at the top and flows downward through the first cooling stage, across a horizontal transition, and then upward through the second cooling stage. The first cooling stage consists of 56 rows of Teflon ${ }^{\mathrm{TM}}$ covered tubes with 6 tubes in each row. The water flow path through the tubes is counter flow to the gas path. The second cooling stage consists of 64 rows of Teflon ${ }^{\mathrm{TM}}$ covered tubes.

Each tube in the IFGT system is covered with Teflon ${ }^{\mathrm{TM}}$, which is extruded over the outside of the tube. Since Teflon ${ }^{\mathrm{TM}}$ is hydrophobic, condensation on the surface of the tube occurs in drops rather than as a film. This allows continuous exposure of most of the surface and improves heat transfer. Teflon ${ }^{\mathrm{TM}}$ is also durable and resistant to abrasion by solid particles in the gas. The inside surfaces of the heat exchanger shell are covered with Teflon ${ }^{\mathrm{TM}}$ sheets. During fabrication, the Teflon ${ }^{\mathrm{TM}}$ covered tubes are pushed through the Teflon ${ }^{\mathrm{TM}}$ tube sheet lining to form a Teflon ${ }^{\mathrm{T}} / \mathrm{Teflon}^{\mathrm{TM}}$ seal, ensuring that all heat exchanger surfaces exposed to the flue gas are protected against acid corrosion. Interconnections between the heat exchanger tubes are made outside the tube sheet and are not exposed to the corrosive flue gas stream.

There are four major sections of the IFGT; the first heat exchanger stage, the interstage transition region, the second heat exchanger stage, and the mist eliminator. Most of the sensible heat is removed from the flue gas in the first heat exchanger stage of the IFGT. Condensation can occur within the first heat exchanger stage if the gas temperature at the tube surface is below the dew point. Some flue gas pollutant removal can occur within the first heat exchanger as the particulate impact the tubes and acid gas condensation occurs. 


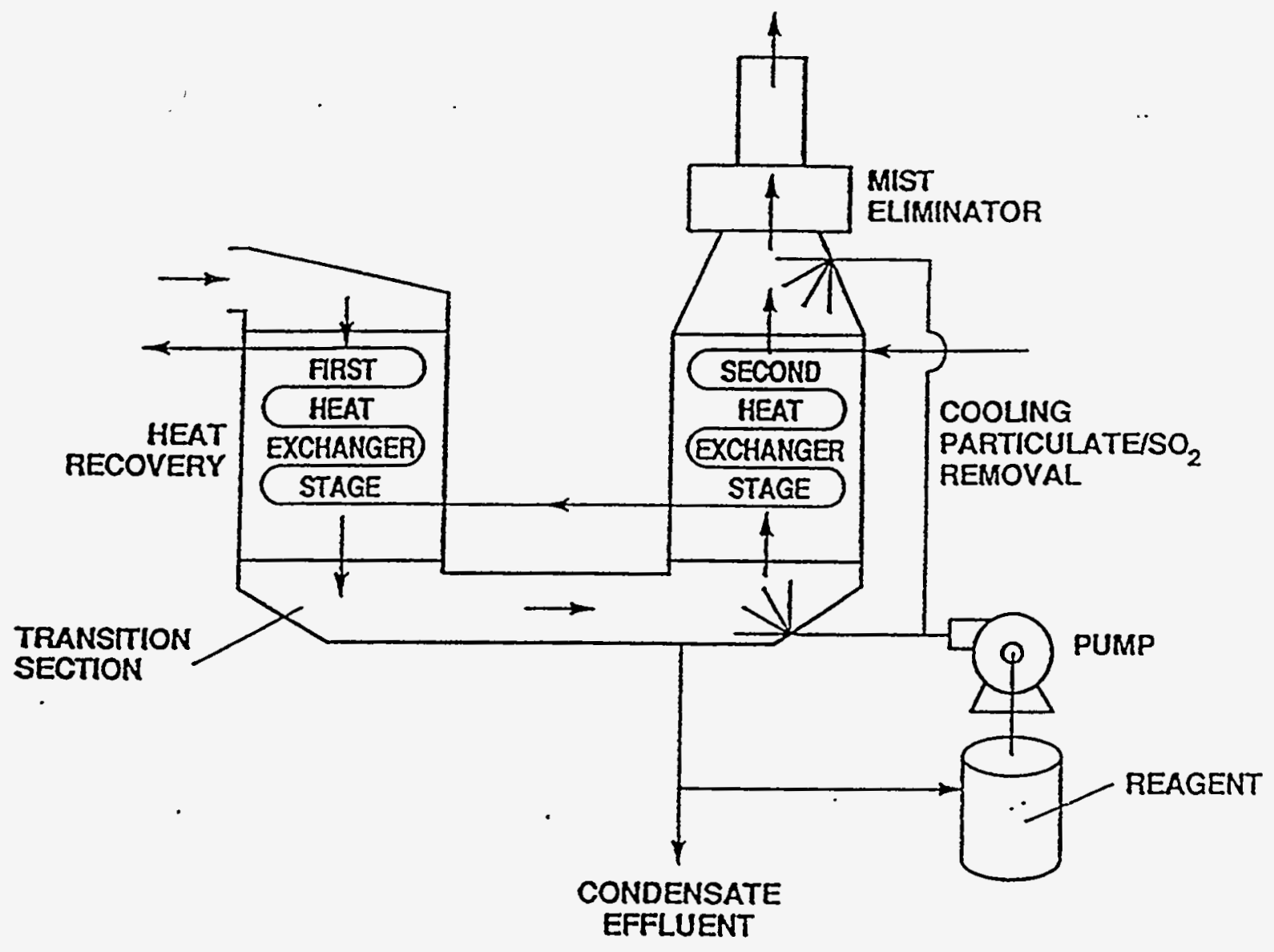

Figure 1 Process Flow Schematic Of The Pilot IFGT Condensing Heat Exchanger 
The inter-stage transition provides a gas flow path between the two heat exchanger stages and also acts as a collection sump for reagent/condensate. The transition is equipped with water spray nozzles that can be used to assist in removing pollutants from the flue gas. The transition piece is made of corrosion resistant fiberglass-reinforced plastic.

The second heat exchanger stage is operated in the condensing mode, removing both latent and sensible heat from the gas along with pollutants. The flue gas in this stage is flowing upward while the liquid droplets in the gas fall downward. This provides a scrubbing mechanism that enhances particulate and pollutant capture. The dimensions and spacing of the heat exchanger tubes ensure that the larger particulate impact the wet tubes where droplet condensation is taking place. Sub-micron size particles act as condensation sites in the gas and are collected in the condensate stream. The top of the second heat exchanger stage is equipped with an alkali reagent spray system to enhance $\mathrm{SO}_{2}$ removal. The condensed gases, particulate, and reacted alkali reagent are collected in the transition section. The condensate/alkali reagent solution is recirculated to the spray system to improve the efficiency of the process. The flue gas outlet of the IFGT system is equipped with a mist eliminator to reduce moisture carryover.

Three plastic sections are installed above the second heat exchanger stage. Each section is about 18 inches in height. The plastic sections contain the second-stage reagent spray nozzles and chevron style mist eliminators. They also provide a disengagement zone for liquid drops entrained in the flue gas as it exits the second heat exchanger stage.

An alkali reagent tank is used to provide the alkali spray for the $\mathrm{SO}_{2}$ removal tests. Sodium carbonate is added to the water in the tank either manually or with a feeder controlled by the $\mathrm{pH}$ controller. A mixer stirs the solution in the tank to dissolve the sodium carbonate. The spent reagent and condensate collected at the bottom of the transition piece during operation is gravity fed to the reagent tank. The reagent tank is equipped with an overflow drain to accommodate the increase in water/reagent inventory from condensation.

The reagent spray can be directed to the top of the second stage heat exchanger or to the transition section. The fiberglass transition piece located between the two heat exchanger stages is equipped with six spray nozzles. The six nozzles are aimed to direct the sprays horizontally into the transition region:

- Four spray nozzles are located on the sidewalls. One pair is located on opposite sidewalls directly under the first heat exchanger stage and the other pair is located about midway between the two heat exchanger stages.

- The other two spray nozzles are located in opposite ends of the transition piece. One nozzle is located directly under the first heat exchanger stage and directs the spray in 
the direction of the gas flow. The second nozzle is located directly below the second heat exchanger stage, with the spray directed against the gas flow stream.

Duct work is installed to bring the exhaust gas from the SBS to the pilot IFGT. The 12-inch insulated duct is tied into the exhaust of the SBS downstream of the baghouse and I.D. fan. The flue gas enters at the top of the first heat exchanger stage and exits out the top of the second heat exchanger stage. A 12-inch non-insulated PVC duct is installed at the exit of the pilot IFGT to an exhaust stack located outside the building.

Gas sampling lines and 4-inch ports for in-situ sampling are located at the inlet and outlet of the IFGT facility. The gas sample lines are used to continuously withdraw flue gas for the online gas sample analyzers. One gas sample line is located in the inlet duct just upstream of the first heat exchanger stage. The other gas sample line is located in the PVC outlet duct. Heattraced lines are used to transport the flue gas samples from the ducts to the gas analyzers. Two four-inch ports are installed both in the inlet and in the outlet flue gas ducts for particulate sampling and other gas sampling as required by the test.

\subsection{SMALL BOILER SIMULATOR (SBS) FURNACE}

Flue gas for Task 2 will be provided by the Small Boiler Simulator (SBS) furnace. This 6 million Btu/hr combustion research facility includes fuel preparation and handling equipment, a furnace and convection pass that provide a prototypical flue gas time-temperature history, a heat exchanger, dry scrubber module and a baghouse. Figure 2 shows an isometric view of the major components of the SBS facility and how they are connected to the pilot IFGT condensing heat exchanger. The IFGT facility is located in a bypass loop downstream of the SBS induced draft fan. For IFGT testing, the dry scrubber module is not in service, and a portion of the flue gas can be bypassed around the baghouse.

The SBS baghouse typically removes $99.9+\%$ of the particulate from the flue gas leaving the furnace. For these tests a measurable particle loading at the IFGT unit will be needed to characterize the particle removal efficiency of the condensing heat exchanger. To provide a measurable particle loading at the CHX facility, approximately $10 \%$ of the flue gas from the SBS furnace will be bypassed around the baghouse. The dry scrubber module will not be in operation, but provides the gas path from the convection pass to the baghouse. The temperature of the flue gas at the baghouse will be maintained at about $300^{\circ} \mathrm{F}$, to provide the maximum temperature possible to the condensing heat exchanger, while maintaining the integrity of the bags. Heat loss and air infiltration between the baghouse and condensing heat exchanger limits the flue gas temperature to about $250^{\circ} \mathrm{F}$ at the inlet of the IFGT system. 


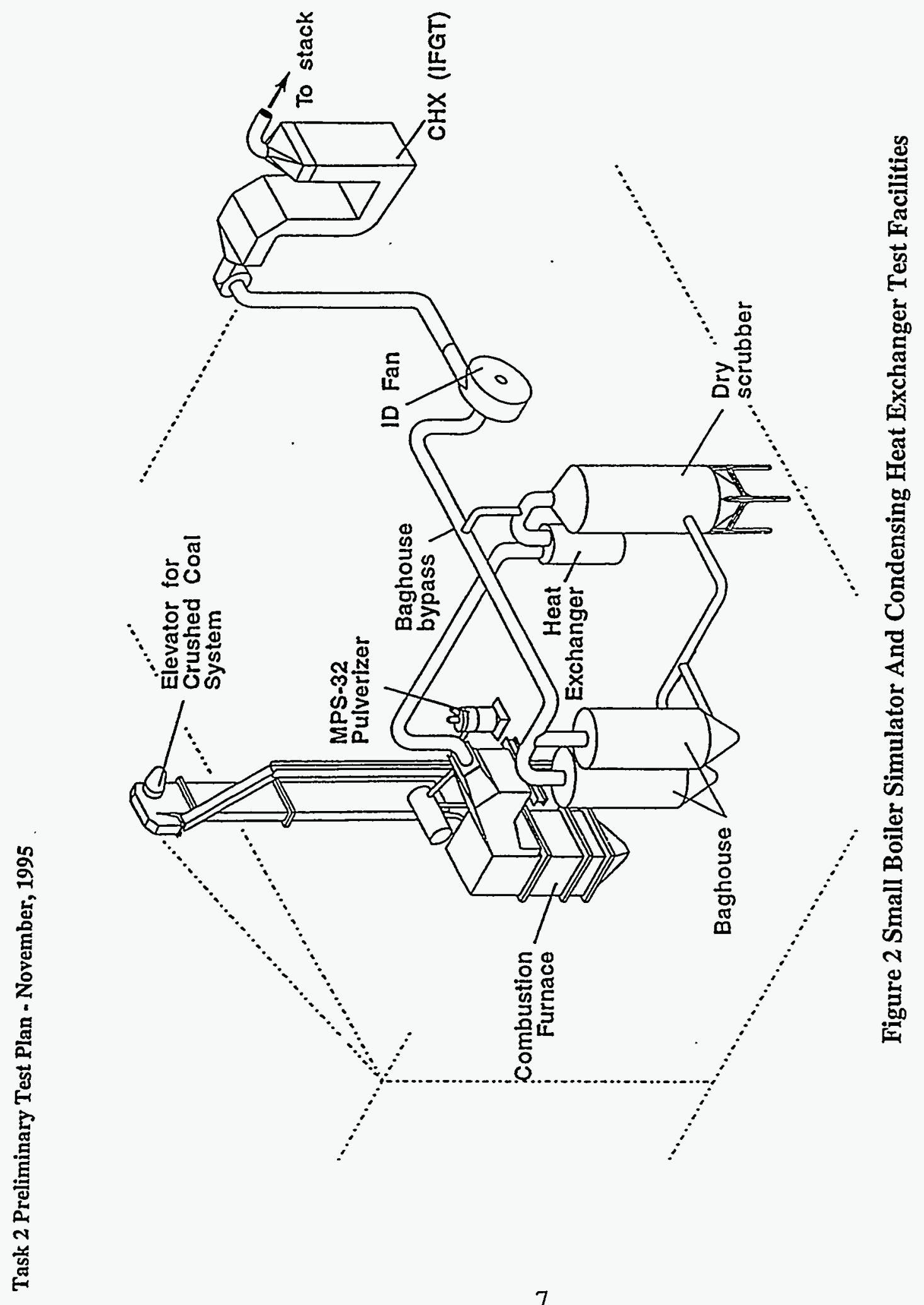




\subsection{GENERAL EXPERIMENTAL APPROACH}

\subsection{FACILITIES OPERATION AND CONTROL}

To complete the test program, B\&W will operate the SBS/IFGT facilities for up to 10 days for each coal. B\&W will provide the necessary personnel to operate the IFGT facility, conduct particulate and air toxics measurements, and collect and analyze samples. A schedule for the test matrix will be developed for the final test plan. The planned schedule includes 2 weeks for testing and 4 weeks for data reduction for each coal. To gather the required information on four coals, approximately 6 months of periodic testing and data reduction will be required.

The SBS facility is operated and controlled independently from the IFGT facility. For these tests the SBS facility will be used to generate representative flue gas that will be routed to, and treated by the IFGT facility. Before testing begins, both facilities will be prepared, raw materials will be procured, and test equipment will be installed and calibrated. The raw materials include up to four different coals and the sodium carbonate (soda ash) reagent.

\section{Small Boiler Simulator Facility}

A prototypical Low $\mathrm{NO}_{\mathrm{x}}$ burner will be installed in the SBS and used to combust the coals. The burner will not be specifically optimized to minimize $\mathrm{NO}_{x}$. Rather, the facility will be operated to attain good combustion with carbon burnout and $\mathrm{CO}$ levels typical of utility power plants. Typical combustion conditions will consist of a heat release of 5 million Btu/hr, excess oxygen at the furnace outlet of $3 \%$ and a $\mathrm{NO}_{x}$ level of approximately $200 \mathrm{ppm}$. Unless specifically identified in the test matrix for a coal, the furnace operation will be maintained at a single combustion operating condition for all tests.

For these tests pollutant removal across the condensing heat exchanger will be based on inlet/outlet measurements, so that specific SBS operating conditions will not be required. However, during the course of testing a single coal, it will be desirable to maintain steady furnace operation during the test day, and to maintain repeatable conditions from day to day.

Typically, the air flow and coal-feed rate required to achieve a specific heat release and excess oxygen is calculated based on an ultimate analysis of the coal. At start-up, the air flow to the furnace is set to the desired value, and the coal-feed rate is adjusted to provide the desired excess oxygen. Minor drift in excess air is compensated with changes to coal-feed rate. Thus, load is allowed to drift slightly to maintain constant excess oxygen and, therefore, furnace combustion conditions. 
For those tests in which coal fly ash is required in the flue gas stream leaving the SBS facility, a portion of the flue gas that normally passes through the SBS baghouse will be diverted around the baghouse. The bypass flow rate (\% of total) will be set based on the fly ash in the coal and the desired fly ash concentration in the flue gas entering the IFGT facility. The percentage bypass flow will be set by reducing the baghouse differential pressure a corresponding percentage. This is based on established pressure-flow relationship for a baghouse which is nearly linear over a limited range.

When operating the SBS facility using coal it is necessary to periodically soot-blow the superheater tubes in the convection pass. The soot-blowing operation provides a short term increase in the flue gas particle loading to the baghouse, and possibly to the IFGT facility. Testing at the IFGT facility will be suspended during the soot-blowing operation to prevent bias in the data due to heavy than normal particle loadings in the flue gas.

A heat exchanger located upstream of the SBS dry scrubber and baghouse is used to set the flue gas temperature. The dry scrubber will not be in service for these tests. The flue gas temperature will be automatically controlled to maintain the flue gas temperature at the baghouse below the maximum temperature of $300^{\circ} \mathrm{F}$. This temperature will be maintained during the course of the testing.

The SBS facility contains a dedicated data acquisition system that provides for detailed characterization of the burner/furnace operating conditions along with manually recorded data. The data acquisition system (DAS) will be used for this test. However, only data that is needed to define the furnace/boiler operation will be reported. These parameters include

- coal feed rate

- primary air flow rate and temperature

- secondary air flow rate and temperature

- excess oxygen concentration at the furnace outlet

- CO concentration

- furnace exit gas temperature

- flue gas temperature at the SBS baghouse

- furnace energy balance

Additionally, the burner used for the test will be documented along with the burner settings (e.g., vane angles).

Although the SBS data is monitored by the DAS continually during boiler operation, the data will be saved only periodically during a test day. The periodic data storage will be concurrent with the manual recording of data at intervals of approximately 2 hours. The data will be averaged to determine daily average conditions and test average conditions. 


\section{Integrated Flue Gas Treatment Facility}

The IFGT facility is located in a by-pass loop downstream of the SBS combustor (Figure 2), and can accommodate up to the full flue gas flow rate corresponding to a heat release of 5 million Btu/hr. The gas flow to the IFGT can be reduced using the IFGT by-pass, without changing the combustion conditions in the SBS combustor.

Typically, the IFGT facility is brought on-line while the SBS furnace is heating up on natural gas fuel. This provides time to set and adjust the cooling water flow rate and for the duct work and IFGT structure to come into thermal equilibrium. The cooling water inlet flow rate and temperature can be controlled independently. The cooling water source is the Alliance city water supply. The temperature of this water defines the lower limit inlet temperature available. The temperature of the inlet water can be raised by mixing in some of the heated cooling water before it is discharged to the drain. The water flow rate is measured with a Micro-Motion mass flow meter.

Reagent flow is provided by a pump connected to the reagent tank. The reagent flow rate is controlled manually with valves, and the location of the reagent spray is likewise controlled with manual valves. A dry hopper and screw feeder on top of the reagent tank provide the feed system for the dry reagent. A pH meter in the reagent supply line along with a set point controller provide a control signal that drives the screw feeder and maintains reagent $\mathrm{pH}$ at the set point. The reagent flow rate and specific gravity is measured with a Micro-motion mass flow meter. The specific gravity is also periodically checked with a hydrometer.

Normally, the flue gas flow rate and temperature are not controlled at the IFGT facility since these are set by the operation of the SBS. However, they are continually monitored and recorded. For partial load tests, a by-pass valve is manually adjusted to obtain the desired flow rate through the IFGT facility. The excess $\mathrm{O}_{2}$ leaving the SBS combustor is nominally set to $3 \%$. However, because of air infiltration at the dry scrubber, baghouse and induced draft fan, the excess $\mathrm{O}_{2}$ at the IFGT facility is typically $1-1 / 2 \%$ to $2 \%$ greater.

The IFGT facility is equipped with a DAS for monitoring and recording IFGT data during a test. All instrumentation providing an electrical signal output are connected to the DAS. The data are updated at 6 to 10 second intervals and during a test the data are recorded at this interval for later data analysis. These data are averaged over the duration of the test to determine the test average conditions.

\subsection{COAL SELECTION}

The coals that have been identified for testing in this Task are a high-sulfur Ohio coal, an unspecified medium-sulfur coal, a lignite coal, and the coal that is used at the Kintigh power 
station that is the site of the EPRI ECTC. With the exception of the ECTC coal, the generic descriptions of the coals allows for latitude in selecting the exact coal to be used (i.e., the mine or coal seam).

To the degree possible, the coals will be selected to best meet the goals of the program. Sulfur content is typically a measure used to select coals. For these tests, other trace coal constituents such as mercury, fluorine, and chlorine are also important to the overall goals of the test. The concentration of these trace elements in coal can vary widely, or be non-existent. However, to provide the smallest measurement uncertainty it is desirable to select coals with relatively high concentration of these elements. Prior to the purchase of the coals for these tests, literature and existing databases on the various coals will be reviewed with the goal of identifying coals with the highest concentrations of these trace elements.

\subsection{TEST CONDITIONS}

The experimental test program proposed for the SBS/IFGT facilities has been designed to investigate the major system operating parameters and are discussed in the following sections. The SBS/IFGT facilities will be operated for up to 10 days on each type of coal to characterize the performance of the IFGT system: Up to four coals will be tested that include a high-sulfur Ohio coal, a medium-sulfur coal, a lignite coal, and the coal that is used at the ECTC. Tests using the ECTC coal will provide data that will be directly applicable to the 5.0 MW IFGT tests at the ECTC scheduled for Phase II. Table 1 summarizes the planned test conditions for Task 2. The following sections provide background information and a summary of the work to be performed.

For each coal a similar series of tests will be conducted. Not all tests will be repeated for every coal, however, because some tests results will not be dependent on the type of coal being fired. The tests have been designed to fully characterize the performance of the IFGT and identify any performance limitations for each of the coals evaluated. Approximately 5 replication tests for $\mathrm{SO}_{2}$ removal efficiency, and thermal efficiency will be included in the test series for each coal. Replication tests are an essential element of a test program and are used to estimate the precision, or repeatability, of the data that has been obtained.

During Task 2, approximately 100 gallons of condensate waste water will be collected in drums for each coal. This condensate waste will be used to evaluate disposal methods in Phase II of the program. Additionally, smaller samples of the condensate will be collected to determine the chemistry of the waste water and to test for mercury, particulate and other heavy metals. 


\subsubsection{Acid Gas Pollutant Removal}

In these tests, $\mathrm{SO}_{2}$ and $\mathrm{NO}_{\mathrm{x}}$ removal, and $\mathrm{HCL}$ and $\mathrm{HF}$ removal will be evaluated. $\mathrm{A}$ preliminary test matrix is shown in Table 1. The majority of tests are in the first test block, where $\mathrm{SO}_{2}$ and $\mathrm{NO}_{\mathrm{x}}$ removal will be investigated. $\mathrm{SO}_{2}$ and $\mathrm{NO}_{\mathrm{x}}$ removal measurements will be conducted over a wide range of operating parameters. A greater or lesser number of tests may be conducted on any given coal so that sufficient data will be collected to determine the $\mathrm{SO}_{2}$ and $\mathrm{NO}_{\mathrm{x}}$ removal characteristics of the IFGT.

At high liquid $\mathrm{pH}$ with $\mathrm{Na}_{2} \mathrm{CO}_{3}$ reagent, the significant resistances to absorption of $\mathrm{SO}_{2}$ are those affecting mass transfer from the gas phase to the alkaline liquid surface. Above a liquid $\mathrm{pH}$ greater than about 7.7, the vapor pressure of $\mathrm{SO}_{2}$ in the liquid is essentially zero. Under these conditions, the major factors for $\mathrm{SO}_{2}$ removal performance are the amount of gas-liquid surface area in the 2 nd stage of the IFGT and flue gas velocity. When the absorbing reagent liquids $\mathrm{pH}$ falls below about 7.7, then the liquid phase $\mathrm{SO}_{2}$ vapor pressure increases which can contribute to a measurable reduction in the absorption of $\mathrm{SO}_{2}$. To investigate these effects, the test matrix includes conditions at a variety of liquid $\mathrm{pH}$, flue gas inlet velocity, and liquid-to gas ratio (L/G).

The absorption of $\mathrm{NO}_{x}$, occurs by mechanisms similar to $\mathrm{SO}_{2}$. However, approximately $95 \%$ of $\mathrm{NO}_{\mathrm{x}}$ is in the form of NO, and the solubility of $\mathrm{NO}$ is less by a factor of about 1300 . While some NO is absorbed in the IFGT system, it is estimated that the mass transfer of $\mathrm{NO}_{\mathrm{x}}$ will be approximately $1 / 20$ th less than what is obtained for $\mathrm{SO}_{2}$. These levels of $\mathrm{NO}_{x}$ absorption may be detectable, and $\mathrm{NO}_{\mathrm{x}}$ measurements at the IFGT inlet and exit will be conducted simultaneously with $\mathrm{SO}_{2}$. Should the initial measurements of $\mathrm{NO}_{x}$ at the inlet and outlet of the IFGT indicate $\mathrm{NO}_{\mathrm{x}}$ removals are too small to accurately quantify, then $\mathrm{NO}_{\mathrm{x}}$ measurements will be suspended for the balance of the tests.

The test matrix includes one test to investigate $\mathrm{HCl}$ and $\mathrm{HF}$ removal. These acid gases are absorbed by mechanisms similar to $\mathrm{SO}_{2}$. However, at the planned IFGT test conditions, the solubility of $\mathrm{HCl}$ and $\mathrm{HF}$ is significantly higher than $\mathrm{SO}_{2}$ and their removal rates are expected to be greater than $98 \%$. The $\mathrm{HCl}$ and $\mathrm{HF}$ removal efficiency will be quantified across the IFGT. The liquid condensate and the sodium carbonate reagent will be analyzed for chloride and fluoride content to better understand the fate of chlorides and fluorides across the IFGT.

\subsubsection{Mercury and Heavy Metals Removal}

The ability of the IFGT to remove mercury and heavy metals from the flue gas and the fate of the mercury will also be determined. Three tests are planned for the range of conditions shown in Table 1. Mercury speciation measurements will be conducted at both the inlet and outlet of the IFGT to quantify total, elemental, and oxidized mercury removal for each of the four coals evaluated. Quantifying the individual species is important since each species has different 
chemical and physical properties. The main forms of mercury emitted in flue gas are elemental ( $\mathrm{Hg}$ ) or the oxidized state (mercuric chloride $\left[\mathrm{HgCl}_{2}\right]$ ). Previous SBS measurements indicate that the total mercury emissions were within the expected range of $1-10 \mathrm{ug} / \mathrm{m} 3 \mathrm{coal}$-fired boilers.

Mercury species are removed from the flue gas by either condensation of elemental $\mathrm{Hg}$ or absorption of $\mathrm{HgCl}_{2}$ into the reagent liquid. Condensation of elemental $\mathrm{Hg}$ is usually not complete as the trace metal concentration is relatively low. However, the lower outlet flue gas temperature of the IFGT $\left(90^{\circ} \mathrm{F}\right)$ over a commercial wet scrubber $\left(120^{\circ} \mathrm{F}-130^{\circ} \mathrm{F}\right)$ may provide for higher levels of elemental mercury removal.

Based on the similar gas-liquid mechanics of commercial wet scrubbers, the IFGT will likely provide for high level of removal for the water-soluble mercury. These forms have aqueous solubilities that are approximately $1000 \mathrm{X}$ higher than that for the elemental form $(\mathrm{Hg})$. The IFGT operating conditions that are expected to affect the mercury species removal efficiency are the outlet flue gas temperature, operating load, reagent spray flux and $\mathrm{pH}$. Mercury removal is anticipated to be enhanced by reduced flue gas temperature, high reagent $\mathrm{pH}$ and increased reagent liquid-to-gas ratio.

To address the final form of the mercury and to evaluate mercury material balances across the IFGT system, the IFGT liquid condensate, collected particulate and the sodium carbonate reagent will be analyzed for mercury concentration. Other streams outside of the IFGT system that will be evaluated for mercury content include the coal feed and upstream baghouse ash.

To summarize, mercury concentration measurements will be conducted on the following process streams:

- Coal feed

- IFGT inlet and outlet gas flows and particulate

- IFGT condensate

- Baghouse ash

Under steady-state operating condition, measurements will be conducted in triplicate to determine the repeatability of the data. Blanks will be run in order to assess the uncertainty in the measurements and to detect unknown sources of contamination.

At the IFGT system inlet, most other trace metals have condensed on the particulate or exist as a submicron fume. The exception is selenium, which can exist in the vapor state at typical IFGT inlet conditions. Provided that selenium is present in the parent coal, the vapor phase and particle concentration will also be measured. 


\subsubsection{Ammonia Removal}

To determine ammonia removal using the IFGT, ammonia will be injected upstream of the IFGT system at a constant measured flow rate. Below $450^{\circ} \mathrm{F}$ ammonia reacts with sulfur trioxide $\left(\mathrm{SO}_{3}\right)$ in the flue gas, so that some of the ammonia may be removed from the flue gas upstream of the IFGT. A preliminary test matrix of 3 tests is shown in Table 1. For all of these tests, removal will be based on measurements at the inlet and outlet of the IFGT. A continuous ammonia analyzer will be used to sequentially measure the ammonia concentration upstream and downstream of the IFGT to determine ammonia removal. Differences between the measured and calculated concentration based on the injection rate of ammonia at the IFGT inlet will be a measure of the ammonia-sulfur reactions. For the ammonia removal tests the concentration of $\mathrm{NO}_{\mathrm{x}}$ at the inlet and outlet of the IFGT will also be measured.

\subsubsection{Particulate Removal}

These tests will determine the overall particulate removal efficiency of the IFGT facility and the removal efficiency as a function of particle size. The particulate loading to the IFGT facility will consist of the fugitive emissions from the SBS baghouse, and a portion of the flue gas from the SBS that is diverted around the baghouse and fed directly to the IFGT.

Total particulate removal will be measured as part of the sampling for mercury and acid gasses. For those measurements the sampling technique requires collection of particulate as well as the gas sample. In addition to those tests, specific tests will be conducted in which the particle size distribution as well as the particle loading at the inlet and outlet of the IFGT will be measured. A preliminary test matrix of 3 tests is shown in Table 1.

The effect of steam injection on particulate removal will also be investigated in this test program. It has been proposed that the addition of steam to water saturated flue gas can enhance the removal of fine particulate. Supersaturating the flue gas causes condensation to occur on particulate, resulting in particle growth. As the smaller submicron size particles increase in diameter they become easier to remove form the flue gas stream. Steam will be injected between the first and second stage of the IFGT and particulate loading measurements will be conducted at the inlet and outlet to the IFGT. The change in particulate removal efficiency and particulate size distribution at the outlet of the IFGT due to steam injection will be determined.

As with wet scrubbers, a fraction of the particulate leaving the IFGT is likely caused by carry out of liquid drops, and possibly the formation of fume in the IFGT. To characterize the effect of carry out on the measured particle loading at the outlet of the IFGT, one test will be conducted using a "clean" flue gas from the SBS baghouse. 
Task 2 Preliminary Test Plan - November, 1995

Table 1 Preliminary List of Test Variables and Range of Conditions For The Pollutant Removal Tests

\begin{tabular}{||c|c|c|c|c|c||}
\hline & $\begin{array}{c}\mathrm{SO}_{2} \\
\text { Removal }\end{array}$ & $\begin{array}{c}\mathrm{HCl} \text { and } \mathrm{HF} \\
\text { Removal }\end{array}$ & $\begin{array}{c}\text { Mercury and } \\
\text { Heavy Metals }\end{array}$ & $\begin{array}{c}\text { Ammonia } \\
\text { Removal }\end{array}$ & $\begin{array}{c}\text { Particulate } \\
\text { Removal }\end{array}$ \\
\hline Planned No. of Tests & $\sim 21$ & 1 & 3 & 1 & 3 \\
\hline $\mathrm{pH}$ & $6,7,7.7+$ & $7.7+$ & $7.7+$ & $7.7+$ & $7.7+$ \\
\hline $\begin{array}{c}\text { Flue Gas Outlet } \\
\text { Temperature }\left({ }^{\circ} \mathrm{F}\right) \\
\text { Dewpoint }=\mathrm{T}_{\mathrm{dp}}\end{array}$ & $\begin{array}{c}\mathrm{T}_{\mathrm{dp} .} \\
\mathrm{T}_{\mathrm{dp}}-20\end{array}$ & $\mathrm{~T}_{\mathrm{dp}}$ & $\begin{array}{c}\mathrm{T}_{\mathrm{dp}}, \\
\mathrm{T}_{\mathrm{dp}}-20\end{array}$ & $\mathrm{~T}_{\mathrm{dp}}$ & $\begin{array}{c}\mathrm{T}_{\mathrm{dp}} \\
\mathrm{T}_{\mathrm{dp}}-20\end{array}$ \\
\hline $\begin{array}{c}\text { Flue Gas Inlet } \\
\text { Velocity (ft/s) }\end{array}$ & 20. to 40. & 40. & $20 . \& 40$. & 40. & 40. \\
\hline $\begin{array}{c}\text { Stage 2 L/G Ratio } \\
\text { (gpm/1000 acfm) }\end{array}$ & 0.5 to 8 & 5 & 5 & 5 & 5 \\
\hline $\begin{array}{c}\text { Inlet Ammonia } \\
\text { (ppm) }\end{array}$ & $(----)$ & $(---)$ & $(---)$ & $10 \& 50$ & $(---))$ \\
\hline $\begin{array}{c}\text { Particulate Loading } \\
\text { (lb/MBtu) }\end{array}$ & $\sim 0 \& 0.3$ & 0.3 & $\sim 0 . \& 0.3$ & 0.3 & $\sim 0 . \& 0.3$ \\
\hline $\begin{array}{c}\text { Steam Injection } \\
\text { (lb/hr) }\end{array}$ & $(----)$ & $(---)$ & $(---)$ & $(---)$ & $\sim 100$ \\
\hline
\end{tabular}




\subsubsection{Heat Recovery}

The heat recovery provided by the IFGT is an integral part of the standard data acquisition. It will be recorded continuously for all of the tests. In addition to this standard data, a series of tests will be conducted to investigate specific heat transfer mechanisms. These include:

- the onset of condensation,

- the onset of measurable condensate flow,

- the effect of the recirculated reagent flow on heat transfer in the second heat exchanger stage.

These heat transfer tests will be conducted on one representative coal. A detailed test matrix will be developed for the Final Test Plan.

\subsection{SAMPLING METHODOLOGY}

This section summarizes the sampling methodology for the process chemistry variables that will be periodically monitored, and presents the sampling and analytical methods to be used during the air toxics test series. All of the analysis procedures will be completed at ARC by B\&W personnel. Sampling ports are in place at the inlet and outlet flues of the IFGT pilot facility for simultaneous flue gas measurements such as cascade impactor measurements, total particulate measurements and gas sampling for mercury, heavy metals and other air toxics. A preliminary sampling and analysis matrix for the solid streams and liquid process streams is given in Table 2. This matrix will be updated in the Final Test Plan.

There are five different types of test blocks in Task 2, each requiring a different combination of sampling and sample analyses. During the test program liquid and solid samples will be obtained, stored and analyzed at sufficient intervals to supplement the test data acquired by the DAS. A methodology for sample size considering detection limits, procedures and test sampling time to get sufficient samples will be included in the final test plan. The most complex sampling and analytical schedule is for the mercury, mercury speciation, and heavy metals test block. Routine sampling and analytical procedures will be used to ensure that:

- $\quad$ process sampling can be safely accomplished,

- samples are representative of the process stream,

- sample contamination is minimized,

- samples are preserved, stored and handled correctly, and

- that sample analyses are traceable to nationally recognized standards. 


\section{Table 2 - Preliminary IFGT Sampling and Analysis Matrix}

Stream Analyses

Particulate Loading

Particulate Size Distribution

Uitimate, Ash, Hv

Total dissolved solids

Total Suspended solids

Specific Gravity

Sulfate

Sulfur

Chloride

Flouride

$\rightarrow \quad$ Sodium

Magnesium

Major Elements

Trace Heavy Metals

Total Mercury

Mercury Speciation

NH3-S Compounds

\begin{tabular}{|c|c|c|c|c|c|c|c|}
\hline $\begin{array}{l}\text { IFGT Inlet } \\
\text { Flue Gas }\end{array}$ & $\begin{array}{l}\text { IFGT Outlet } \\
\text { Flue Gas }\end{array}$ & Coal & $\begin{array}{c}\text { Baghouse } \\
\text { Ash }\end{array}$ & Particulate & $\begin{array}{l}\text { Na2CO3 } \\
\text { Reagent }\end{array}$ & $\begin{array}{l}\text { Reagent } \\
\text { Supply }\end{array}$ & $\begin{array}{c}\text { makeup } \\
\text { Water }\end{array}$ \\
\hline$P, M, H, A$ & $P, M, H, A$ & 3. & & & 1.1 & : & \\
\hline$P$ & $P$ & 4.1. & & & 3 & 1. & 4 \\
\hline 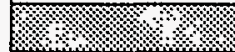 & & Each Coal & & \% & (3) & (খ্য & $\sqrt{2}$ \\
\hline 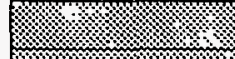 & (I. & & & & 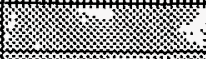 & Steady State & \\
\hline (4) & 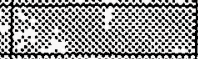 & ২יব & 1.1. & ?. & & Steady State & \\
\hline & & & & & & Steady State & \\
\hline : & (1) & (4) & 28 & 4.1 .8$. & 3 & Steady State & \\
\hline (1. & L. & Each Coal & & & & Steady State & \\
\hline $\mathrm{H}$ & $\mathrm{H}$ & Each Coal & & & $\mathrm{H}$ & & $\bar{H}$ \\
\hline $\mathrm{H}$ & $H$ & Each Coal & & & $\mathrm{H}$ & & $\bar{H}$ \\
\hline 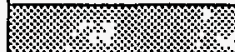 & (2) & & & & $1 \times$ batch & Steady State & \\
\hline & (m) & & & & & Steady State & \\
\hline (17/, & 3.1. & & & & & Steady State & M \\
\hline$M$ & $M$ & Each Coal & & $M$ & & & $\bar{M}$ \\
\hline $\bar{M}$ & $M$ & Each Coal & $M$ & $M$ & $M$ & & $\bar{M}$ \\
\hline$M$ & $M$ & & & & & & \\
\hline 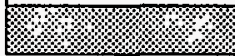 & 1. & 2 & 3 & $P$ & : & & \\
\hline
\end{tabular}

\section{Test Block}

$\mathrm{H}-\mathrm{HCl}$ and HF Testing.
$\mathrm{M}$ - Mercury Testing.
$\mathrm{P}-$ Particulate Testing.
$\mathrm{S}-\mathrm{SO} 2, \mathrm{NO}$, and Heat Recovery Testing.
A - Ammonia Removal Testing.


For example, to obtain liquid samples from the IFGT that are consistent with the measured flue gas constituents, approximately 1-2 hours at steady operating conditions will be required. Representative sampling procedures will be defined for solids such as the coal feed and sodium carbonate reagent.

The air toxics trace substance sampling and analytical techniques selected are those either approved or recommended by the EPA. Table 3 lists the sampling methods to be employed for all air toxics sampling. Table 4 provides the appropriate method of sample preparation and the method reference. Tables 5, 6, and 7 outline the analytical methods to be employed for solid streams (coal, ash, and $\mathrm{Na}_{2} \mathrm{CO}_{3}$ ), flue gas impingers and liquid process streams. Table 8 summarizes the standard analytical methods used to characterize the coal stream.

Flue gas from the IFGT inlet and exit will be continuously sampled and analyzed for $\mathrm{SO}_{2}$, $\mathrm{NO}_{x}$ and $\mathrm{O}_{2}$ by an extractive gas analyzer system. The system will consist of six analyzers and associated heated hose and flue gas conditioning equipment that is consistent with EPA Method $6 \mathrm{C}$.

\subsection{DATA ACQUISITION AND REDUCTION}

\subsection{TEST DATA}

Most of the IFGT facility operating data will be obtained by a computerized data acquisition system. B\&W utilizes a PC-based computerized Data Acquisition System (DAS) to monitor and record all instrumentation with an electronic signal output. The process measurements that will be obtained for data reduction will consist of temperatures, pressures, flow rates of gases and liquids, and flue gas species such as $\mathrm{SO}_{2}, \mathrm{O}_{2}$, and $\mathrm{NO}_{\mathrm{x}}$. Table 9 contains a list of continuous monitoring instrumentation planned for Task 2. Most of the data will be collected approximately every 10 seconds by the DAS and stored for later data reduction. Some of the data, such as barometric pressure, and gas side pressure drop will be manually recorded. A Chessell multichannel chart recorder will be used to continuously record the outputs of the gas analyzers and other selected instrumentation. 
Table 3 - IFGT Sampling Methods

\begin{tabular}{||l|l||}
\hline \multicolumn{2}{|c|}{ Sampling Methods } \\
\hline Target Substance & \multicolumn{1}{c|}{ Method } \\
\hline Gas Streams \\
\hline Metals & Draft EPA Method 29 \\
\hline Chloride, Fluoride & EPA Method 26A \\
\hline Liquid Streams & EPRI Method A1 \\
\hline Solid Streams \\
\hline Coal & ASTM D - 197 \\
\hline Particulate & EPA Method 5 \& Anderson Mark III \\
\hline $\mathrm{Na}_{2} \mathrm{CO}_{3}$ & Grab/Composite \\
\hline
\end{tabular}


Task 2 Preliminary Test Plan - November, 1995

Table 4 IFGT Sample Preparation Techniques

\begin{tabular}{||l|l|l|l||}
\hline \multicolumn{1}{|c|}{ Analytes } & \multicolumn{1}{|c|}{ Matrix } & \multicolumn{1}{|c|}{$\begin{array}{c}\text { Preparation } \\
\text { Technique }\end{array}$} & Method Reference \\
\hline Metals & Coal & Microwave Digestion & ASTM E926-88 \\
\hline Mercury & Coal & Oxygen Bomb & ASTM D3684-78 \\
\hline Chloride, Fluoride & Coal & Oxygen Bomb & ASTM D2361 \\
\hline Metals & Particulate & Microwave Digestion & ASTM E926-88 \\
\hline Mercury & Particulate & Acid Digestion & EPA 7471A \\
\hline Chloride, Fluoride & Particulate & Acid Digestion & EPA SW3051 \\
\hline Metals & $\mathrm{Na}_{2} \mathrm{CO}_{3}$ & Microwave Digestion & ASTM C-25 \\
\hline Mercury & $\mathrm{Na}_{2} \mathrm{CO}_{3}$ & Acid Digestion & EPA 7471A \\
\hline Chloride, Fluoride & $\mathrm{Na}_{2} \mathrm{CO}_{3}$ & Acid Digestion & EPA SW3051, mod \\
\hline Metals & Solids & Microwave Digestion & ASTM E926-88 \\
\hline Mercury & Solids & Acid Digestion & EPA 7471A \\
\hline Chloride, Fluoride & Solids & Acid Digestion & EPA SW3051, mod \\
\hline Metals (As, Se) & Liquid Streams & Acid Digestion & EPA SW3020 \\
\hline Metals (Other) & Liquid Streams & Microwave Digestion & EPA SW3010 \\
\hline Mercury & Ljquid Streams & Acid Digestion & EPA 3015 \\
\hline Chloride, Fluoride & Liquid Streams & None & \\
\hline & & \multicolumn{2}{|l}{} \\
\hline
\end{tabular}


Task 2 Preliminary Test Plan - November, 1995

Table 5 Analytical Methods for Solid Streams

\begin{tabular}{||l|l|l||}
\hline \multicolumn{1}{|c|}{ Analytes } & \multicolumn{1}{|c|}{$\begin{array}{c}\text { Analytical } \\
\text { Method }\end{array}$} & \multicolumn{1}{|c|}{ Method Title } \\
\hline $\begin{array}{l}\mathrm{Ba}, \mathrm{Be}, \mathrm{Cd}, \mathrm{Cr}, \mathrm{Co}, \mathrm{Mn}, \\
\mathrm{Ni}, \mathrm{Pb}\end{array}$ & GFAAS & $\begin{array}{l}\text { Graphite Furnace Atomic Absorption } \\
\text { Spectroscopy }\end{array}$ \\
\hline $\mathrm{As}, \mathrm{Se}$ & HGAAS & $\begin{array}{l}\text { Hydride Generation Atomic Absorption } \\
\text { Spectroscopy }\end{array}$ \\
\hline $\mathrm{Hg}$ (Coal) & $\begin{array}{l}\text { CVAAS ASTM } \\
\text { D364-78 }\end{array}$ & $\begin{array}{l}\text { Standard Method for Total Mercury in Coal } \\
\text { by Oxygen Bomb/Cold Vapor Atomic } \\
\text { Absorption Spectroscopy }\end{array}$ \\
\hline $\mathrm{Hg}$ (Others) & $\begin{array}{l}\text { CVAAS } \\
\text { SW7471/SW846 }\end{array}$ & $\begin{array}{l}\text { Mercury in Solids or Semi Solids } \\
\text { Waste/Cold Vapor Atomic Absorption } \\
\text { Spectroscopy }\end{array}$ \\
\hline Chloride (Coal) & Oxygen Bomb, & ASTM D4208-88 \\
\hline Fluoride (Coal) & Oxygen Bomb, & ASTM D3761-91 \\
\hline Chloride (Others) & IC & ASTM D4327, modified \\
\hline Fluoride (Others) & IC & ASTM D4327, modified \\
\hline Carbon (Coal) & Gravimetric & ASTM D3178-89 \\
\hline \hline
\end{tabular}

Others - Ash, Reagent, Solids 
Task 2 Preliminary Test Plan - November, 1995

Table 6 Analytical Methods for Flue Gas Impingers ,

\begin{tabular}{|l|l|l|}
\hline \multicolumn{1}{|c|}{ Analytes } & Analytical Method & \multicolumn{1}{c|}{ Method Reference } \\
\hline $\begin{array}{l}\mathrm{Ba}, \mathrm{Be}, \mathrm{Cd}, \mathrm{Cr}, \mathrm{Co}, \mathrm{Mn}, \\
\mathrm{Ni}, \mathrm{Pb}\end{array}$ & GFAAS & $\begin{array}{l}\text { Graphite Furnace Atomic Absorption } \\
\text { Spectroscopy }\end{array}$ \\
\hline $\mathrm{As}, \mathrm{Se}$ & HGAAS & $\begin{array}{l}\text { Hydride Generation Atomic Absorption } \\
\text { Spectroscopy }\end{array}$ \\
\hline $\mathrm{Hg}$, Elemental & CVAAS & $\begin{array}{l}\text { Cold Vapor Atomic Absorption } \\
\text { Spectroscopy }\end{array}$ \\
\hline $\mathrm{Hg}$, Ionic & CVAAS & $\begin{array}{l}\text { Cold Vapor Atomic Absorption } \\
\text { Spectroscopy }\end{array}$ \\
\hline Chloride, Fluoride & IC & Ion Chromatography \\
\hline
\end{tabular}

Table 7 Analytical Methods for Liquid Process Streams

\begin{tabular}{|l|l|l|}
\hline \multicolumn{1}{|c|}{ Analytes } & Analytical Method & \multicolumn{1}{c|}{ Method Reference } \\
\hline $\begin{array}{l}\mathrm{Ba}, \mathrm{Be}, \mathrm{Cd}, \mathrm{Cr}, \mathrm{Co}, \mathrm{Mn}, \\
\mathrm{Ni}, \mathrm{Pb}\end{array}$ & GFAAS & $\begin{array}{l}\text { Graphite Furnace Atomic Absorption } \\
\text { Spectroscopy }\end{array}$ \\
\hline $\mathrm{As}, \mathrm{Se}$ & HGAAS & $\begin{array}{l}\text { Hydride Generation Atomic Absorption } \\
\text { Spectroscopy }\end{array}$ \\
\hline $\mathrm{Hg}$, Total & CVAAS & $\begin{array}{l}\text { Cold Vapor Atomic Absorption } \\
\text { Spectroscopy }\end{array}$ \\
\hline Chloride, Fluoride & IC & Ion Chromatography \\
\hline
\end{tabular}


Task 2 Preliminary Test Plan - November, 1995

Table 8 Coal Analytical Methods

\begin{tabular}{||l|l|l||}
\hline \multicolumn{1}{|c|}{ Analyte } & \multicolumn{1}{c|}{ Analytical Method } & \multicolumn{1}{c|}{ Method Reference } \\
\hline Moisture & Gravimetric & ASTM D3173-87 \\
\hline Heating Value & Calorimetry & ASTM D2015-19 \\
\hline Ultimate Analysis & & \\
\hline $\mathrm{C}, \mathrm{H}$ & Gravimetric & ASTM 3178-89 \\
\hline $\mathrm{S}$ & Instrumental & ASTM D4239-85, Method C \\
\hline $\mathrm{N}$ & Titrimetric & ASTM 3179-89 \\
\hline Ash & Gravimetric & ASTM 3179-89 \\
\hline
\end{tabular}




\section{Table 9 - IFGT Preliminary Continuous Monitoring Instrumentation List}

\begin{tabular}{|c|c|c|}
\hline MEASUREMENT & UNITS & METHOD \\
\hline Ammonia Flow Rate & $\mathrm{lb} / \mathrm{hr}$ & Manual \\
\hline Barometric Pressure & In. $\mathrm{Hg}$ & Manual \\
\hline Cooling Water Flow Rate & $\mathrm{lb} / \mathrm{hr}$ & DAS \\
\hline Cooling Water Inlet Temperature & Deg F & DAS \\
\hline Cooling Water Interstage Temperature & DegF & DAS \\
\hline Cooling Water Outlet Temperature & Deg F & DAS \\
\hline Flue Gas Flow Orifice Static & in $\mathrm{H} 2 \mathrm{O}$ & DAS \\
\hline Flue Gas Flow Orifice DP & in $\mathrm{H} 2 \mathrm{O}$ & DAS \\
\hline Flue Gas NH3 Conc. At Inlet/Outlet & Ppm (DRY) & DAS \\
\hline Flue Gas $\mathrm{O} 2$ Conc. At Inlet & $\%$ (Dry) & DAS \\
\hline Flue Gas $\mathrm{O} 2$ Conc. At Outlet & $\%$ (Dry) & DAS \\
\hline Flue Gas NOx Conc. At Inlet & ppm (Dry) & DAS \\
\hline Flue Gas NOx Conc. At Outlet & ppm (Dry) & DAS \\
\hline Flue Gas SO2 Conc. At Inlet & ppm (Dry) & DAS \\
\hline Flue Gas $\mathrm{SO} 2$ Conc. At Outlet & ppm (Dry) & DAS \\
\hline Flue Gas Flow Orifice Temperature & DegF & DAS \\
\hline Gas Temperature @ Inlet To Analyzers & $\operatorname{Deg} F$ & DAS \\
\hline Gas Temperature @ Module 1 Inlet & Deg $F$ & DAS \\
\hline Gas Temperature @ Module1 Outlet & Deg $F$ & DAS \\
\hline Gas Temperature @ Module 2 Inlet & Deg F & DAS \\
\hline Gas Temperature @ Module 2 Outlet & Deg $F$ & DAS \\
\hline Gas Temperature @ Outlet Flue & Deg $F$ & DAS \\
\hline Make-up Water Flow Rate & $\mathrm{lb} / \mathrm{hr}$ & DAS \\
\hline Spray Nozzle Pressure & PSIG & Manual \\
\hline Flue Gas Orifice Delta Pressure & In. WC & Manual \\
\hline Flue Gas Orifice Pressure & In. WC & Manual \\
\hline Flue Gas Pressure 1st Stage Inlet & In. WC & Manual \\
\hline Flue Gas Delta Pressure ist Stage & In. WC & Manual \\
\hline Flue Gas Delta Pressure 2nd Stage & In. WC & Manual \\
\hline Flue Gas Delta Pressure Demister & In. WC & Manual \\
\hline Reagent Blowdown Flow & $\mathrm{lb} / \mathrm{hr}$ & DAS \\
\hline Reagent Flow Rate & $\mathrm{lb} / \mathrm{hr}$ & DAS \\
\hline Reagent Temperature & Deg F & DAS \\
\hline Reagent pH - Supply & $-\log [H+$ activity $]$ & DAS \\
\hline Reagent pH - Return & $-\log [H+$ activity] & DAS \\
\hline Steam Injection & $\mathrm{lb} / \mathrm{hr}$ & Manual \\
\hline TC@ Tube Row 3 - Stage 1 & Deg $F$ & DAS \\
\hline TC @ Tube Row6 - Stage 1 & $\operatorname{Deg} F$ & DAS \\
\hline TC@ @ube Row 9 -Stage 1 & Deg $F$ & DAS \\
\hline TC @ Tube Row 12 -Stage 1 & Deg $F$ & DAS \\
\hline TC@ Tube Row 15 - Stage 1 & Deg $F$ & DAS \\
\hline
\end{tabular}




\section{Table 9 - Continued}

\begin{tabular}{|c|c|c|}
\hline MEASUREMENT & UNITS & METHOD \\
\hline TC @ Tube Row 18 - Stage 1 & DegF & DAS \\
\hline TC @ Tube Row 21 -Stage 1 & DegF & DAS \\
\hline TC @ Tube Row 24 -Stage 1 & Deg $F$ & DAS \\
\hline TC@ @ube Row 27 - Stage 1 & DegF & DAS \\
\hline TC@Tube Row 30 W - Stage 1 & $\operatorname{Deg} F$ & DAS \\
\hline TC @ Tube Row $30 \mathrm{E}$-Stage 1 & Deg $F$ & DAS \\
\hline TC@Tube Row 30 C -Stage 1 & Deg $F$ & DAS \\
\hline TC@Tube Row 33 -Stage 1 & Deg $F$ & DAS \\
\hline TC@ Tube Row 36 -Stage 1 & Deg $F$ & DAS \\
\hline TC@ Tube Row 39 - Stage 1 & Deg $F$ & DAS \\
\hline TC @ Tube Row 42 - Stage 1 & Deg $F$ & DAS \\
\hline TC @ Tube Row 45 - Stage 1 & Deg $F$ & DAS \\
\hline TC @ Tube Row 48 - Stage 1 & Deg $F$ & DAS \\
\hline TC@ @ Tube Row 51 -Stage 1 & Deg $F$ & DAS \\
\hline TC@Tube Row 54 -Stage 1 & Deg $F$ & DAS \\
\hline TC @ Tube Row 3 -Stage 2 & Deg $F$ & DAS \\
\hline TC@ Tube Row 6 -Stage 2 & Deg $F$ & DAS \\
\hline TC @ Tube Row 9 -Stage 2 & Deg $F$ & DAS \\
\hline TC@ Tube Row 12 -Stage 2 & DegF & DAS \\
\hline TC@ Tube Row 15 -Stage 2 & Deg $F$ & DAS \\
\hline TC@ Tube Row 18 -Stage 2 & Deg F & DAS \\
\hline TC @ Tube Row 21 - Stage 2 & $\operatorname{Deg} F$ & DAS \\
\hline TC@ Tube Row 24 - Stage 2 & $\operatorname{Deg} F$ & DAS \\
\hline TC @ Tube Row 27 -Stage 2 & DegF & DAS \\
\hline TC@ @ube Row 30 W - Stage 2 & DegF & DAS \\
\hline TC@ Tube Row 30 E -Stage 2 & $\operatorname{Deg} F$ & DAS \\
\hline TC@ Tube Row 30 C -Stage 2 & Deg F & DAS \\
\hline TC@ Tube Row 33 -Stage 2 & $\operatorname{Deg} F$ & DAS \\
\hline TC @ Tube Row 36 - Stage 2 & DegF & DAS \\
\hline TC @ Tube Row 39 --Stage 2 & DegF & DA.S \\
\hline TC @ Tube Row 42 - Stage 2 & Deg $F$ & DAS \\
\hline TC @ Tube Row 45 - Stage 2 & DegF & DAS \\
\hline TC @ Tube Row 48 - Stage 2 & $\operatorname{Deg} F$ & DAS \\
\hline TC@ Tube Row 51 -Stage 2 & Deg'F & DAS \\
\hline TC @ Tube Row 54 -Stage 2 & Deg $F$ & DAS \\
\hline Transmitter Power Supply Voltage & VDC & DAS \\
\hline
\end{tabular}


Data will be analyzed during the test program to determine if adjustments are necessary to the remaining test blocks. The data collected during the tests of the four coals will be analyzed to determine removal efficiency of the IFGT for the various air pollutants including:

$\mathrm{SO}_{2}$

Mercury by species

Total particulate

Particulate by particle size

$\mathrm{NO}_{x}$
Ammonia

$\mathrm{HCl} \& \mathrm{HF}$

Ammonia-sulfur compounds

Selenium and other heavy metals, if present

The removal efficiencies of the IFGT for these pollutants will be determined as a function of the test variables. In addition to this data, the thermal performance of the IFGT measured during the tests will be analyzed. Energy and condensate mass balances on the IFGT will be made for steady-state operating conditions.

\subsection{QUALITY ASSURANCE}

The Research \& Development Division (R\&DD) has two levels of quality assurance under which the R\&D work is performed. They are Standard Practice, and Specified Quality Assurance (SQA). Standard Practices are those activities normally performed by the Research and Development Division when no specific customer requirements are imposed. These practices are well recognized as an outstanding base quality system for research work by organizations such as the U.S. DOE, U.S. DOD, Electric Power Research Institute, Gas Research Institute, and many others. These practices are described in the STANDARD PRACTICE MANUAL and are further implemented by R\&DD Administration Procedures.

This project will utilize the R\&DD Standard Practice quality assurance system. The Task Leader and the R\&DD management will ensure these requirements are met and appropriate documentation is on file. Specific activities will include:

- The certification or standardization of all measurement standards and measuring and test equipment used on the project to ensure that measurements made are accurate and reproducible in terms of nationally recognized standards. Suppliers of instruments and calibration services are audited periodically to determine that calibration requirements are being satisfied.

- Throughout the test program, several measurements, such as flue gas analyzers and $\mathrm{pH}$ transmitters will be standardized before and after use with calibration standards that are traceable to NIST. 
- Grab samples of various solids and liquids will have adequate chain of custody control.

- Mercury determinations will include the use of blanks to account for any background concentrations that may be present.

\subsection{REPORTING}

A Topical report will be prepared that is a complete and detailed evaluation of the testing conducted during Task 2 of the Project. The report will include a description of the facilities, instrumentation used for making the measurements, a description of measurement techniques, and test procedures as appropriate.

The report will include test data, calculated results for each coal tested, and applicable observations by personnel witnessing the tests. The performance of the IFGT as a pollutant removal device will be presented and the test results from the different coals will be compared. The report will include coal analyses, the measured pollutant concentrations at the inlet and outlet of the IFGT facility, pollutant concentration in the blow down liquid stream and pollutant removal efficiencies across the IFGT facility.

\subsection{SITE RESTORATION/WASTE DISPOSAL}

After the completion of the test program, the SBS combustor and IFGT pilot scale facility will be restored to pre-test conditions. The interior of the SBS furnace is insulated with refractory to simulate full-scale furnace temperatures. Over a period of time this insulation gradually erodes and must be periodically replaced or repaired. At the conclusion of testing, the insulation will be repaired or replaced as required.

Waste water condensate collected during testing of each of the four test series will also require disposal. The condensate waste water will be analyzed to determine the presence and concentration of toxic or hazardous materials. Based on the analysis, the condensate will be disposed in an environmentally acceptable manner that is in compliance with EPA and local regulations. Selected local waste water discharge limits are shown in Table 10. A suitable quantity of waste water for each coal, about 100 gallons, will be saved for bench scale testing under Phase II. 
Task 2 Preliminary Test Plan - November, 1995

Table 10 Selected City of Alliance, Ohio Local Discharge Limits

\begin{tabular}{|l|c|}
\hline \multicolumn{1}{|c|}{ Element } & Discharge Limit (ug/L) \\
\hline Cadmium & 25 \\
\hline Copper & 1000 \\
\hline Lead & 500 \\
\hline Mercury & 1 \\
\hline Zinc & 2500 \\
\hline
\end{tabular}

